Patients diagnosed with esophageal carcinoma should be first evaluated for presence of comorbid conditions (mainly cardiac or pulmonary diseases) that may preclude the patient from undergoing surgery [2-5]. Those patients who are fit for surgery should undergo preoperative tumor staging. First thing required in fit patients is to exclude the presence of distant metastasis or unresectable disease. For such purpose, helical CT scan and more recently Positron Emission Tomography (PET) scanning are typically employed (diagnostic accuracy $70 \%$ to $80 \%$ ) [6]. Those patients that appear to be resectable based on those imaging techniques should pursue a more detailed local-regional staging ( $T$ and N stage) (Table 1) [6-20]. EUS has been proven to be most accurate imaging technique for such purpose [6 -20] (Table 2 ).

1. Number or site of nodes for nodal staging? How to improve accuracy of nodal staging?

Lymph node staging of esophageal cancer patients by EUS has classically relied on 4 EUS features that are based on size (lymph node width greater than $10 \mathrm{~mm}$ ), shape (round), echogenicity (echopoor pattern) and lymph node border (smooth), that have been proposed to be suggestive of malignancy [21,22]. Although these criteria allow one to differentiate benign from malignant lymph nodes in esophageal carcinoma patients with an accuracy close to $80 \%$, none of them is diagnostic of malignancy alone $[21,22]$. It has been reported that when all four features suggestive of malignancy are present, there is an $80-100 \%$ probability that the lymph node is malignant; unfortunately, only $25 \%$ of malignant nodes will present all 4 criteria diagnostic of malignancy $[21,22]$. These results demonstrate limitations of current EUS criteria for preoperative determination of lymph node staging.

\section{Nodal staging: Number or site of nodes? How to improve accuracy? Is FNA always necessary? Junctional tumors - what's $\mathbf{N}$ and what's M?}

\author{
E. Vazquez-Sequeiros \\ Gastroenterology Division, Hospital Ramon y Cajal, Madrid, \\ Alcala University, SPAIN
}

\section{Introduction}

Endoscopic ultrasound (EUS) allows one to identify the presence of lymph nodes in the mid and posterior mediastinum, the perigastric area and the celiac axis region [1]. EUS, by means of endoscopic ultrasound guided fine needle aspiration biopsy (EUS FNA), may also be employed for procurement of a tissue diagnosis in a minimally invasive fashion [1]. This has been proven to be useful in a number of gastrointestinal and pulmonary malignancies. This review article focuses on nodal staging of esophageal cancer and attempts to answer the following questions: 1 . Number or site of nodes for nodal staging? How to improve accuracy of nodal staging? 2. Is FNA always necessary? 3. Junctional tumors - what's $\mathrm{N}$ and what's $\mathrm{M}$ ?

Correspondence: Enrique Vazquez-Sequeiros, M.D., Ph.D. · C/Diego de Torres 9-3A · Alcala de Henares. Madrid. 28801 - SPAIN - Phone: +34-669897935 - Fax: +34-918835348·E-mail: evazquezs@hotmail.com

Bibliography: Endoscopy 2006; 38 (S1): S4-S8 @ Georg Thieme Verlag KG Stuttgart · New York · ISSN 0013-726X · DOI 10.1055/s-2006-946642
Efforts have been made to improve EUS accuracy for preoperative lymph node staging of esophageal cancer, and to provide a more reliable diagnosis [23-25]. It has been proposed that by adding some additional criteria to the classical EUS lymph node criteria, one may better predict which lymph nodes are benign or malignant in nature [23]. These "modified EUS malignant lymph node criteria" consist in the 4 classical ones (Lymph node $\geq 5 \mathrm{~mm}$ in width; round shape; hypoechoic pattern; smooth border) plus 3 additional criteria that include lymph node location (celiac region), number of lymph nodes identified on EUS exam $(\geq 5)$ and presence of an advanced T stage tumor based on EUS exam (Tumor was T3/4) [23]. These additional features included in the modified EUS criteria arose from prior investigations performed in lymph node staging of esophageal carcinoma [26-28]. Performance characteristics (sensitivity, specificity and overall accuracy) of the Standard and Modified EUS malignant lymph node criteria were assessed in a prospective cohort of 144 patients ( $84 \%$ of patients were N1, and $16 \%$ were N0), with results being compared by using the Receiver Operating Characteristics (ROC) curves, with the Area Under the Curve (AUC) representing the overall diagnostic accuracy of EUS lymph node criteria (standard and modified). ROC curves allow one to measure the sensitivity and specificity of each set of criteria at different cut off points, determining the most accurate cut off point to differentiate between benign and malignant lymph nodes (knowing that an AUC of 0.90-1.0 is excellent, AUC of $0.80-0.90$ is good, 
Table 1 TNM and Stage Grouping for Esophageal Carcinoma (A.J.C.C. classification) [20]

\begin{tabular}{|c|c|c|c|}
\hline \multicolumn{2}{|c|}{ Primary Tumor $(\mathrm{T})$ : } & \multicolumn{2}{|c|}{ Distant Metastases (M): } \\
\hline Tx: & Primary tumor cannot be assessed & Mx: & Distant metastases cannot be assessed. \\
\hline T0: & No evidence of primary tumor. & M0: & No distant metastases. \\
\hline Tis: & Carcinoma in situ & M1: & Distant metastases. \\
\hline T1: & Tumor invades lamina propria or submucosa. & 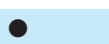 & Tumors of the lower thoracic esophagus: \\
\hline T2: & Tumor invades muscularis propria. & & M1a : Metastases in celiac lymph nodes. \\
\hline T3: & Tumor invades adventitia. & & M1b: Other distant metastases. \\
\hline \multirow[t]{2}{*}{ T4: } & Tumor invades adjacent structures. & $\bullet$ & Tumors of the mid-thoracic esophagus: \\
\hline & & & M1a: Not applicable. \\
\hline \multicolumn{2}{|c|}{ Regional Lymph Nodes (N): } & & M1b: Non-regional lymph nodes and/or \\
\hline Nx: & Regional lymph nodes cannot be assessed. & & other distant metastases. \\
\hline N0: & No regional lymph node metastases. & $\bullet$ & Tumors of the upper thoracic esophagus: \\
\hline \multirow[t]{2}{*}{ N1: } & Regional lymph node metastases. & & M1a: Metastases in cervical nodes. \\
\hline & & & M1b: Other distant metastases. \\
\hline Stage Group: & T stage & N stage & M stage \\
\hline Stage 0: & Tis & No & M0 \\
\hline Stage I: & $\mathrm{T} 1$ & No & M0 \\
\hline Stage IIA: & $\mathrm{T} 2 / \mathrm{T} 3$ & No & M0 \\
\hline Stage IIB: & $\mathrm{T} 1 / \mathrm{T} 2$ & N1 & M0 \\
\hline Stage III: & T3 & N1 & M0 \\
\hline Stage IV: & Any $T$ & Any $N$ & M1 \\
\hline Stage IVA: & Any $T$ & Any $N$ & M1a \\
\hline Stage IVB: & Any $T$ & Any $\mathrm{N}$ & M1b \\
\hline
\end{tabular}

Table 2 Preoperative TN staging accuracy of CT and EUS in esophageal carcinoma patients [19]

\begin{tabular}{llll}
\hline & $\begin{array}{l}\text { Patients } \\
(\boldsymbol{n})\end{array}$ & $\begin{array}{l}\text { T Stage (range) } \\
\text { (\%) }\end{array}$ & $\begin{array}{l}\text { N Stage (range) } \\
\text { (\%) }\end{array}$ \\
\hline CT & 1154 & $\begin{array}{l}45 \\
(40-50)\end{array}$ & $\begin{array}{l}54 \\
(48-71)\end{array}$ \\
\hline & & $\begin{array}{l}\text { EUS } \\
(59-92)\end{array}$ & $\begin{array}{l}77 \\
(50-90)\end{array}$ \\
\hline
\end{tabular}

AUC of $0.70-0.80$ is fair, AUC of $0.60-0.70$ is poor, and AUC of $0.50-0.60$ implies the test fails). According to the gold standard adopted in this study, modified EUS criteria for lymph node staging were found to be more accurate than standard criteria (ROC curve/area under the curve 0.88 vs 0.78 , respectively (Fig. 1). In other words, larger numbers of lymph nodes, celiac lymph nodes, and deeper mural invasion all portend greater likelihood of N1 disease (26-28). The maximum accuracy of modified EUS criteria (86\%) was observed when presence of 3 or more of the 7 modified EUS criteria were required to diagnose lymph node malignancy (Fig.1). Although no single criteria was predictive of malignancy, the cut off number of 6 or more of the modified criteria (cut off at that point) provided a specificity of $100 \%$ and in that cohort of patients (prevalence of malignant lymph nodes: $84 \%$ ) had a positive predictive value of $100 \%$ (40/40, 95\% CI: $90-$ $100 \%$ ) (Fig. 1). Thus all patients with one or more lymph nodes with $\geq 6$ modified EUS criteria had N1 stage disease in that cohort of patients. Additionally, the cut off of 1 or more of the modified EUS criteria (cut off at that point) provided a sensitivity of $100 \%$ and in that cohort of patients (prevalence of benign lymph nodes: $16 \%$ ) the negative predictive value was $100 \%$ (21/ 21, 95\% CI: $82-100 \%$ ) if zero criteria were present (Fig. 1). That is, none of the patients included in that study who had lymph nodes with $<1$ positive modified EUS criteria presented with N1 stage disease. A detailed analysis of single criteria employed for lymph node diagnosis (multiple logistic regression analysis) disclosed that lymph node width $\geq 5 \mathrm{~mm}$, round shape, $\geq 5$ lymph nodes identified on EUS exam, and T3/4 tumor as per EUS assessment were the criteria that best predicted malignancy in that cohort of patients.

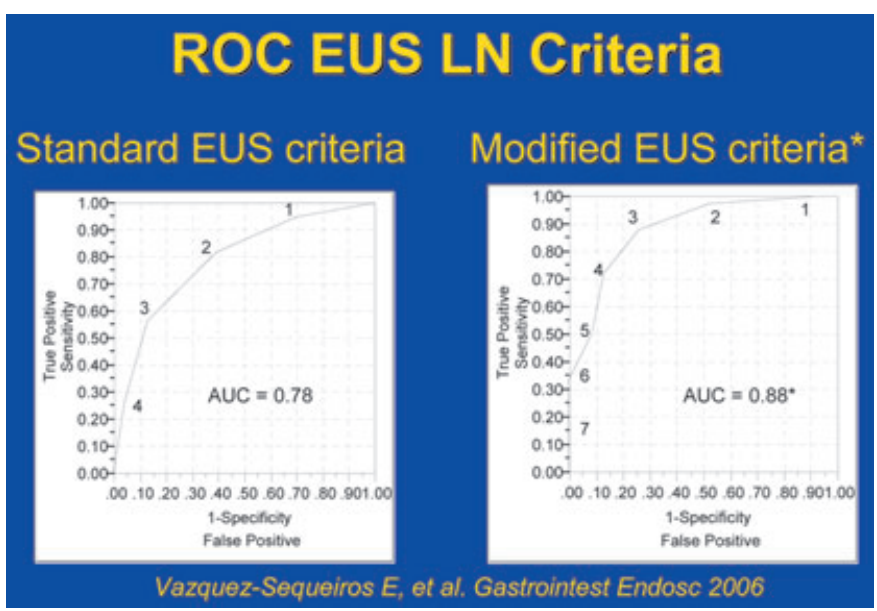

Fig. 1 Performance charateristics for preoperative lymph node staging of esophageal carcinoma [23]. 
EUS EXAM

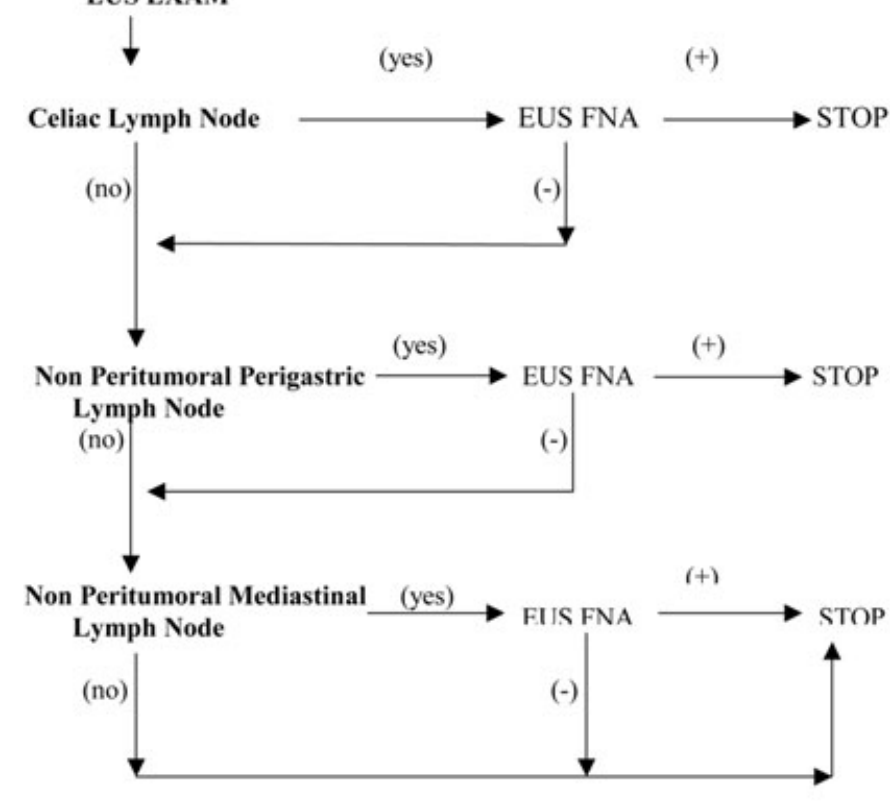

Fig. 2 Algorithm for selection of lymph nodes undergoing EUS FNA in preoperative staging of esophageal cancer [34].

EUS accuracy depends on operator's experience [29 - 32]. Several controlled studies have demonstrated that experienced (> 50/75 EUS exams in esophageal cancer cases), but not inexperienced endosonographers (< 20 EUS exams in esophageal cancer) have good agreement and high accuracy for $\mathrm{N}$ staging of esophageal cancer [29-32]. A number of technical factors (balloon overinflation, oblique scanning, and inadequate use of higher scanning frequencies) appear to be responsible for errors among inexperienced endosonographers [29-32]. Mistakes occurred in lymph node staging of esophageal cancer have been associated with benign lymph nodes larger that $10 \mathrm{~mm}$ (overstaging them as $\mathrm{N} 1$ ), and understaging of lymph nodes as N0 in cases of microscopic infiltration of the node by tumor that is beyond the resolution capabilities of the echoendoscopes.

\section{Is FNA always necessary?}

Some investigators have suggested that EUS FNA may help improve the accuracy of $\mathrm{N}$ staging by providing cytologic confirmation of malignant spread of the disease [1,23 - 26]. This hypothesis is based on prior studies that have clearly demonstrated EUS FNA has an elevated sensitivity, specificity and accuracy for periintestinal lymph nodes [1,23-26]. Retrospective studies have shown EUS FNA accuracy for esophageal cancer lymph node staging is superior to EUS alone (accuracy EUS vs EUS FNA 70 versus 93 per cent, $\mathrm{p}<0.05$ ) [23-26,33]. These results were confirmed by a later study conducted at the Mayo Clinic comparing in a prospective and blinded fashion the performance characteristics of helical CT, EUS and EUS FNA for preoperative lymph node staging of esophageal carcinoma [34]. Authors followed a strict algorithm for lymph node selection, starting by sampling celiac lymph nodes (if present), continuing by lymph nodes located in the perigastric space and finally sampling lymph nodes located in the periesophageal space in a non peritumoral location (Fig. 2). The endosonographers were blinded to CT findings, and committed to a $\mathrm{N}$ stage prior to performing the EUS-FNA part
Table 3 Prospective lymph node staging of esophageal carcinoma: CT, vs EUS vs EUS FNA [34]

\begin{tabular}{|llll}
\hline & Sensitivity & Specificity & Accuracy \\
\hline $\mathbf{n} \% \mathbf{( 9 5 \%}$ C.I.) & & & \\
\hline CT & $14 / 48$ & $25 / 28$ & $39 / 76$ \\
& $29 \%(17 \%, 44 \%)$ & $89 \%(72 \%, 98 \%)$ & $51 \%(40 \%, 63 \%)$ \\
\hline EUS & $34 / 48$ & $22 / 28$ & $56 / 76$ \\
\hline EUS FNA & $71 \%(56 \%, 83 \%)$ & $79 \%(59 \%, 92 \%)$ & $74 \%(62 \%, 83 \%)$ \\
\hline p-value & $40 / 48$ & $26 / 28$ & $66 / 76$ \\
\hline CT vs EUS & $83 \%(70 \%, 93 \%)$ & $93 \%(77 \%, 99 \%)$ & $87 \%(77 \%, 94 \%)$ \\
\hline CT vs EUS FNA & $<0.001^{*}$ & & \\
\hline EUS vs EUS FNA & 0.058 & 0.257 & $0.003 *$ \\
\hline
\end{tabular}

(EUS-FNA was performed with the asistance of an on site cytopathologist). Table 3 demonstrates the superior accuracy of EUS FNA over EUS and helical CT.

In another study (previously mentioned in this review), the authors aimed to identify a newly defined combination of EUS lymph node criteria that have sufficient sensitivity and specificity to preclude the need for EUS FNA in certain clinical situations [23]. For such purpose, the modified set of criteria previously described were designed and evaluated. Results of the study showed that all patients with one or more lymph nodes with $\geq$ 6 modified EUS criteria had N1 stage disease, and none of the patients included in this study who had lymph nodes with $<1$ positive modified EUS criteria presented with N1 stage disease. Therefore, in those patients with either $\geq 6$ or $<1$ criteria, EUS FNA may be avoided as we may predict if the lymph node is malignant or benign in nature, and EUS FNA results are unlikely to change lymph node stage in those patients. When direct costs assotiated with a routine EUS FNA approach for esophageal cancer staging vs a selective EUS FNA approach (EUS FNA is avoided in those patients with $\geq 6$ or $<1$ lymph node criteria, $42 \%$ of patients included in that study) was compared, the selective EUS FNA practice was associated with a cost saving of \$117.84 per patient ( $\$ 16,968.37$ in the total cohort of patients evaluated) (2004 US Medicare reimbursement fees employed for calculations). Although these numbers may differ depending on the payer, procedure reimbursement, clinical setting and country, avoiding EUS FNA in $42 \%$ of esophageal carcinoma patients will reduce costs without diminishing test accuracy.

\section{Junctional tumors - what's $\mathbf{N}$ and what's $\mathbf{M}$ ?}

Tumors located at the distal esophagus and/or invading the gastroesophageal junction are usually adenocarcinoma, and present a characteristic and distinct pathway for lymph node spread of the disease. This type of tumor tends to spread to the periesophageal ganglia first, and then into the abdomen (subcardial area, gastrohepatic ligament and celiac axis region). More recent TNM classifications have considered that lymphatic spread of the disease into the celiac axis region represents metastatic disease, and therefore those patients have been classified as M1a disease, as this implies a prognosis similar to patiens with liver metastasis [20]. Patients with M1 disease are not considered candidates 
for cure, and palliative measures are typically indicated. For this reason, it seems important to look carefully at the celiac axis area to investigate for presence of metastatic spread of the disease to distant lymph nodes. Furthermore, it appears to be important as well, to confirm the nature of celiac lymph nodes by means of cytology/histology, as important treatment decisions will depend on this. Although prevalence of celiac lymphadenopathy depends on the type of esophageal cancer patients evaluated at each institution, some reports have found that 40 of 198 esophageal cancer patients undergoing EUS examination for preoperative staging may present malignant appearing lymph nodes in the celiac axis area [35]. From those 40 patients, EUS-FNA was able to prove malignancy in the nodes in 31 patients ( 78 percent). From the remaining nine patients, 8 had no malignant lymph (correctly assessed by EUS-FNA and confirmed by surgery), and one patient was a false negative by EUS-FNA. These excellent results have been confirmed by other studies conducted at different institutions, in which EUS was shown to have a sensitivity for celiac lymph node detection of $77 \%$ (95\% CI: $67-88 \%$ ), and a specificity of $85 \%$ (95\% CI: $74-96 \%)$, with an overall accuracy for EUS-FNA of celiac lymph nodes as high as $98 \%$ (95\% CI: 90-100\%) (25). These results support the use of EUS and EUS FNA for the evaluation of the celiac axis region in search for metastatic nodes.

\section{Summary}

In summary, EUS and EUS FNA are the most accurate techniques for preoperative local-regional staging of esophageal carcinoma, once CT and/or PET scan have excluded the presence of distant metastasis. An experienced endosonographer, familiar with the EUS technique, and the inclusion of lymph node location, number of nodes and EUS T stage as diagnostic criteria may help improve preoperative lymph node staging accuracy in esophageal cancer. EUS FNA helps improve diagnostic accuracy in esophageal cancer staging. However, in patients with a certain number of EUS lymph node criteria, EUS FNA may be avoided without affecting diagnostic accuracy. In tumors of the distal esophagus detection and biopsy of celiac lymph nodes may be successfully perdormed by EUS and FNA.

\section{References}

${ }^{1}$ Wiersema MJ, Vilmann P, Giovannini M, Chang KJ, Wiersema LM. Endosonography-guided fine-needle aspiration biopsy: diagnostic accuracy and complication assessment. Gastroenterology 1997; 112: 1087-1095

2 Pera M, Cameron AJ, Trastek VF, Carpenter HA, Zinsmeister AR. Increasing incidence of adenocarcinoma of the esophagus and esophagogastric junction. Gastroenterology 1993; 104: 510-513

3 DeMeester TR, Zaninotto G, Johansson KE. Selective therapeutic approach to cancer of the lower esophagus and cardia. J. Thorac. Cardiovasc. Surg. 1988; 95: $42-54$

${ }^{4}$ Hagen JA, Peters JH, DeMeester TR. Superiority of extended en bloc esophagogastrectomy for carcinoma of the lower esophagus and cardia. J. Thorac. Cardiovasc. Surg. 1993; 106: 850-859

${ }^{5}$ Walsh TN. Noonan N. Hollywood D. Kelly A. Keeling N. Hennessy TP. A comparison of multimodal therapy and surgery for esophageal adenocarcinoma [see comments]. N Engl J Med. 1996; 335 (7): 462 - 467

${ }^{6}$ Flamen P, Lerut A, Van Cutsem E, De Wever W, Peeters M, Stroobants S, Dupont P, Bormans G, Hiele M, De Leyn P, Van Raemdonck D, Coosemans W, Ectors N, Haustermans K, Mortelmans L. Utility of positron emision tomography for the staging of patients with potentially operable esophageal carcinoma. J Clin Oncol 2000; 18 (18): 3202 - 3210

${ }^{7}$ Murata Y, Suzuki S, Hashimoto H. Endoscopic ultrasonography of the upper gastrointestinal tract. Surg Endosc. 1988; 2: 180-183

8 Tio TL, Coene PPLO, den Hartog Jager FCA, Tytgat GNJ. Preoperative TNM classification of esophageal carcinoma by endosonography. Hepato-gastroenterol 1990; 37: 376-381

${ }^{9}$ Dittler HJ, Bolschweiler E, Siewert JR. Was leistet die endosonographie im praoperativen Staging des Osophaguskarzinoms. Dtsch Med Wschr 1991; 116: $561-566$

${ }^{10}$ Vilgrain V, Mompoint D, Palazzo L, Menu Y, Gayet B, Ollier P, Nahum H, Fakete F. Staging of oesophageal carcinoma: comparison of results with endoscopic sonography and CT. Am J Radiol 1991; 155: 277-281

${ }^{11}$ Botet JF, Lightdale CJ, Zauber G, Gerdes H, Urmacher C, Brennan MF. Preoperative staging of esophageal cancer: Comparison of endoscopic US and dynamic CT. Radiology 1991; 181: 419-425

${ }^{12}$ Grimm H, Binmoeller KF, Hamper K, Koch J, Henne-Burns D, Soehendra N. Endosonography for preoperative locorregional staging of esophageal and gastric cancer. Endoscopy 1993; 25: 224-230

13 Rosch T, Lorenz R, Zenker K, von Wichert A, Dancygier H, Hofler H, Siewert JR, Classen M. Local staging and assessment of resectability in carcinoma of the esophagus, stomach and duodenum by endoscopic ultrasonography. Gastrointest. Endosc 1992; 38: 460 - 467

14 Quint LE, Glazer GM, Orringer MB. Esophageal imaging by MR and CT: study of normal anatomy and neoplasms. Radiology 1985; 156: 727 - 731

15 Petrilo R, Balzarini L, Bidoli P, Ceglia E, D'Ippolito G, Tess JD, Musumeci R. Esophageal squamous cell carcinoma: MRI evaluation of the mediastinum. Gastrointest Radiol 1990; 15: 275-278

16 Takashima S, Takeuchi N, Shiozaki H, Kobayashi K, Morimoto S, Ikezoe J, Tomiyama N, Harada K, Shogen K, Kozuka T. Carcinoma of the esophagus: CT v.s. MR imaging in determining resectability. Am J Radiol 1991; 156: 297-302

${ }^{17}$ Lehr L, Rupp N, Siewert JR. Assessment of resectability of esophageal cancer by computed tomography and magnetic resonance imaging. Surgery. 1988; 103: $344-350$

${ }^{18}$ Koch J, Robert AHJr. Staging of esophageal cancer: Computed Tomography, Magnetic Resonance Imaging and Endoscopic Ultrasound. Seminars in Roentgenology 1994; 29: $364-372$

${ }^{19}$ Rosch T. Endoscopic staging of esophageal cancer: a review of literature results. Gastrointest. Endosc. Clin North Am 1995; 5: 537-547

${ }^{20}$ Fleming ID, Cooper JS, Henson DE. In: AJCC Cancer Staging Manual. Lippincott-Raven (Eds). Philadelphia: 1997: pp 65-69

${ }^{21}$ Catalano MF, Sivak MVJr, Rice T, Gragg LA, van Dam J. Endosonographic features predictive of lymph node metastasis. Gastrointest Endosc 1994; 40: $442-446$

22 Bhutani MS, Hawes RH, Hoffman BJ. A comparison of the accuracy of echo features during endoscopic ultrasound ( EUS ) and EUS-guided fine needle aspiration for diagnosis of malignant lymph node invasion. Gastrointest Endosc 1997; 45: $474-479$

${ }^{23}$ Vazquez-Sequeiros E, Levy MJ, Clain JE, Schwartz DA, Harewood GC, Salomao D, Wiersema MJ. Routine vs. selective EUS-guided FNA approach for preoperative nodal staging of esophageal carcinoma. Gastrointest Endosc 2006; 63 (2): 204-211

${ }^{24}$ Reed CE, Mishra G, Sahai AV, Hoffman BJ, Hawes RH. Esophageal cancer staging: improved accuracy by endoscopic ultrasound of celiac lymph nodes. Ann Thorac Surg 1999; 67: 319-322

${ }^{25}$ Eloubeidi MA, Wallace MB, Reed CE, Hadzijahic N, Lewin DN, Van Velse A, Leveen MB, Etemad B, Matsuda K, Patel RS, Hawes RH, Hoffman BJ. The utility of EUS and EUS-guided fine needle aspiration in detecting celiac lymph node metastasis in patients with esophageal cancer: a single center experience. Gastrointest Endosc 2001; 54: 714 - 719

${ }^{26}$ Wallace MB, Hawes RH, Sahai AV, Van Velse A, Hoffman BJ. Dilation of malignant esophageal stenosis to allow EUS guided fine-needle aspiration: safety and effect on patient management. Gastrointest Endosc 2000; 51: 309-313

27 Vazquez-Sequeiros E, Burgart LJ, Wang L, Harmsen WS, Zinsmeister AR, Allen M et al. Influence of Lymph Node Micrometastases (LNMM) Detected by Immunohistochemistry (cytokeratin AE1/AE3 monoclonal antibody) on Relapse Free Survival in Patients with Node Negative Esophageal Carcinoma (EC). Gastroenterology 2002; 122: 1815-1821

${ }^{28}$ Rosch T, Lorenz R, Zenker K, von Wichert A, Dancygier H, Hofler H, Siewert JR, Classen M. Local staging and assessment of resctability in carcinoma of the esophagus, stomach and duodenum by endoscopic ultrasonography. Gastrointest Endosc 1992; 38 (4): 460 - 467 
${ }^{29}$ Catalano MF, Sivak MVJr, Bedford RA, Falk GW, van Stolk R, Presa F, Van Dam J. Observer variation and reproducibility of endoscopic ultrasonography. Gastrointest Endosc 1995; 41: 115-120

${ }^{30}$ Palazzo L, Burtin P. Interobserver variation in tumor staging. Gastrointest. Endosc Clin North Am 1995; 5: 559-567

${ }^{31}$ Fockens PF, Van den Brande J, van Dullemen HM, van Lanschot J.Jan B, Tytgat GNJ. Endosonographic T-staging of esophageal carcinoma: a learning curve. Gastrointest Endosc 1996; 44: 58 - 62

32 Massari M, Cioffi U, De Simone M, Ugo Cioffi, De Simone M, Lattuada E, Montorsi M, Segalin A, Bonavina L. Endoscopic ultrasonography for preoperative staging of esophageal carcinoma. Surg Laparosc Endosc 1997; 7: $162-165$

${ }^{33}$ Vazquez-Sequeiros E, Norton ID, Clain JE, Wang KK, Affi A, Allen M, Deschamps C, Miller D, Salomao D, Wiersema MJ. Impact of endoscopic ultrasound guided fine-needle aspiration on lymph node staging in patients with esophageal carcinoma. Gastrointest Endosc 2001; 53 (7): $751-757$

${ }^{34}$ Vazquez-Sequeiros E, Wiersema MJ, Clain JE, Norton ID, Levy M, Romero Y, Salomao D, Dierkhising R, Zinsmeister AR. Impact of lymph node staging on esophageal carcinoma therapy. Gastroenterology 2003; 125 (6): 1626 - 1635

35 Giovannini M, Monges G, Seitz JF, Moutardier V, Bernardini D, Thomas P, Houvenaeghel G, Delpero JR, Giudicelli R, Fuentes P. Distant lymph node metastasis in esophageal cancer: Impact of endoscopic ultrasound-guided biopsy. Endoscopy 1999; 31: 536 - 540 